\title{
A EDUCAÇÃO NOS INTRAMUROS DO SISTEMA PRISIONAL: DESAFIOS E POSSIBILIDADES PARA HUMANIZAÇÃO E EMANCIPAÇÃO PELO TRABALHO
}

Priscila de Lima Gomes*, Léia Adriana da Silva Santiago, Marco Antônio de Carvalho, Willian

\author{
Rayner Lima \\ *E-mail: priscila.gomes@ifg.edu.br \\ DOI: 10.15628/rbept.2020.11596
}

Artigo submetido em set./2020 e aceito em dez/2020

\begin{abstract}
RESUMO
O grande desafio do sistema prisional é promover emancipação e humanização. Portanto, apresentamos a educação profissional como proposta de uma formação humana integral, na perspectiva de reinserção social e no mundo do trabalho. Baseamo-nos na pesquisa bibliográfica do tipo documental, que traz as concepções de autores marxistas acerca dessa vertente. Como resultados, verificamos a baixa escolarização, o tempo ocioso, a falta de oportunidade de trabalho e de políticas públicas como fatores que contribuem para a reincidência criminal. Dessa forma, vê-se a Educação Profissional, Técnica e Tecnológica como possibilidade para uma formação omnilateral e para a contemplação do trabalho como princípio educativo.
\end{abstract}

Palavras-Chave: Educação libertadora. Sistema penitenciário. Educação nas prisões.

\section{THE EDUCATION WITHIN THE WALLS OF THE PENITENTIARY SYSTEM: CHALLENGES AND POSSIBILITIES OF HUMANIZATION AND EMANCIPATION THROUGH LABOR}

\begin{abstract}
The great challenge in the prison system is to promote the emancipation and humanization. Therefore, we present as a proposal for the professional education an integral human formation, in the perspective of social reinsertion and also in the world of labor. We based on the documental bibliographic research, which brings conceptions from Marxist authors about this strand. As results, we checked the low education rate, idle time, lack of work opportunity and public politics as items that contribute on the criminal recidivism. This way, it is seen that the Professional, Technical and Technological Education are a possibility of omnilateral formation and of contemplating the labor as an educative principle.
\end{abstract}

Keywords: Liberating education. Penitentiary system. Education in prisons.

\section{INTRODUÇÃO}

A população carcerária tem apresentado alto índice de crescimento. Muitas pessoas são presas diariamente por praticarem crimes de categorias diversas, porém o sistema prisional não está preparado para receber e reeducar tamanha demanda e, dessa forma, poucas são as ações realizadas com o intuito de realmente reeducar esses sujeitos. Na maioria dos casos, as 
prisões se tornam escolas de criminalidade, onde aqueles mais experientes, que cumprem penas restritivas de liberdade em decorrência de crimes mais bárbaros, perpetuam seus ensinamentos aos menos experientes nesse submundo. Mesmo que esses conhecimentos não estejam de acordo com as normas de conduta social e moral, ainda assim ocorre a transmissão do saber, levando o indivíduo a se apropriar de saberes que não dispunha anteriormente. Nesse sentido, cabe refletir, a partir de Vygotsky (1984), essa interação social que tem como produto a apropriação do conhecimento, como zona de desenvolvimento proximal (ZDP). Apesar da negligência do Estado, o qual detém a tutela dos apenados, é importante destacar que estes estão amparados pela Lei de Execução Penal (Lei no 7.210 de 1984), que preconiza em seus artigos $10^{\circ}$ e $11^{\circ}$ que, a fim de orientar o retorno à convivência em sociedade e prevenir o crime, é dever do Estado assegurar ao preso assistência educacional, além de outras garantias, como saúde, material, jurídica, social e religiosa. Essa lei também disciplina, em sua seção $\mathrm{V}$, a assistência educacional a ser ofertada ao encarcerado (BRASIL, 1984).

A responsabilidade do Estado em garantir o acesso à educação básica obrigatória ao indivíduo independe deste estar ou não com sua liberdade cerceada está regulamentada pela Lei no 9.394/96 (Lei de Diretrizes e Bases da Educação Nacional), em seu artigo 5ำ, como direito público e subjetivo, podendo ser exigido por qualquer cidadão ou entidade, inclusive acionando o poder público para que a lei seja cumprida (BRASIL, 1996). Além de todo esse aparato legal, atendendo ao Plano Nacional de Educação em vigor, Lei no 13.005 de 2014, em estratégias da meta $\mathrm{n}^{\circ}$ 9, é também assegurado o direito ao ensino fundamental e médio por meio da oferta de Educação de Jovens e Adultos às pessoas privadas de liberdade, inseridas em estabelecimentos penais (BRASIL, 2014). Os fundamentos legais foram apresentados com o objetivo de compreender que existem legislações que amparam o direito do recluso em ser assistido por uma educação de qualidade. É um direito de todos e dever do Estado, resguardado até mesmo no bojo de nossa Lei maior, a Constituição Federal, em seu artigo 205 (BRASIL, 1988).

Sabe-se que apenas uma proposta pedagógica não é suficiente para superar os desafios atuais. No entanto, a partir de uma nova concepção de educação nos intramuros do presídio, é possível refletir acerca de novos caminhos a serem trilhados que vão além da realidade presente na grande maioria dos complexos prisionais. É uma concepção de educação que vai além de um "passatempo" para ocupar o tempo ocioso e manter o ambiente pacífico, ao contrário, isso será a consequência, e não a finalidade, pois o cumprimento de pena deve ser pensado como uma possibilidade de mudança na mentalidade e comportamento do indivíduo que cumpre pena restritiva de liberdade.

Desse modo, a proposta de desenvolvimento deste trabalho foi a partir de pesquisas bibliográficas, a fim de compreender a problemática que envolve a educação no contexto do sistema penitenciário. Para tanto, este artigo destaca o que se tem previsto na legislação e como ocorre a aplicação dessas leis no sistema prisional na cidade de Aparecida de Goiânia no que tange à oferta de um ensino de qualidade que comtemple a formação omnilateral dos reeducandos, conforme as propostas da Educação Profissional e Tecnológica. Estudiosos desse tipo de educação trazem reflexões e bases conceituais sobre 
a importância do trabalho para o ser humano e para sua reinserção na sociedade após o cumprimento da pena, por esse motivo essas concepções serão consideradas neste artigo.

Defendemos que seja ofertada aos reclusos uma formação integral, pois ela compreende a totalidade do indivíduo, em todas as suas dimensões, que são o trabalho, a ciência e a cultura, de forma omnilateral. Manacorda (2010, p. 94), amparado pelos pressupostos de Marx, conceitua omnilateralidade como o "desenvolvimento total, completo, multilateral, em todos os sentidos, das faculdades e das forças produtivas, das necessidades e da capacidade da sua satisfação". Nesse sentido, Ciavatta (2005) aponta essa concepção de formação humana integral como uma possibilidade de cisão da dualidade entre trabalho manual e intelectual, marcado historicamente pela divisão social do trabalho. Nesse contexto, é possível superar a formação para o trabalho que se limita à dimensão operacional, oportunizando ao reeducando o desenvolvimento de suas capacidades e potencialidades.

\section{PERCURSO METODOLÓGICO}

Para Gil (1999), a pesquisa se fundamenta por meio de várias ações que visam solucionar um problema por meio da investigação, para obter as informações necessárias mediante o emprego de procedimentos científicos. Esta pesquisa apresenta a abordagem qualitativa e tem como base metodológica a análise documental (leis, projetos, portarias, doutrinas e jurisprudências) e bibliográfica (livros, periódicos, teses e dissertações), além de visitas à Penitenciária Coronel Odenir Guimarães, localizada em Aparecida de Goiânia, para saber acerca das possibilidades de ocupação e tipos de atividades desenvolvidas com os detentos. Este estudo consistiu na análise crítica e rigorosa à luz dos teóricos Marx, Gramsci, Saviani, Manacorda e Ciavatta, além dos estudiosos que são referências em pesquisas no contexto da educação e trabalho em unidades prisionais, como Julião e Rizzi, entre outros. Além disso, buscamos trazer reflexões sobre os princípios da Educação Profissional e Tecnológica que auxiliam no entendimento do potencial educativo e libertador da educação pelo trabalho.

\section{RESULTADOS E DISCUSSÕES}

Sauer e Julião (2012) explicitam por meio do Documento-Referência os frutos do Seminário Educação nas Prisões, promovido pelo Ministério da Educação através do Conselho Nacional de Educação. No referido documento, relatam que a implementação da política de educação no cárcere surgiu em decorrência da articulação dos Ministérios da Justiça e da Educação, apoiados pela Unesco. Inicialmente, em 2005, ocorreu como proposta de articulação a favor do Programa Nacional de Educação para o Sistema Prisional e, consequentemente, no ano seguinte, realizaram o I Seminário Nacional de Educação para o Sistema Penitenciário e, no ano de 2007, o segundo. Consta 
no Documento-Referência que o seminário realizado em 2012, em Brasília, foi planejado a fim de efetivar as normativas contidas no Parecer do Conselho Nacional de Educação e Câmara de Educação Básica (CNE/CEB) no 4/2010 e Resolução CNE/CEB no 2/2010, que dispõe sobre as Diretrizes Nacionais para a oferta de educação de Jovens e adultos em situação de privação de liberdade nos estabelecimentos penais. Esse Seminário teve como estratégia partilhar o conhecimento, boas práticas e experiências eficazes no contexto prisional.

Dentre os principais êxitos, Sauer e Julião (2012) apontam a aprovação das Diretrizes Nacionais para a oferta de educação nas instituições penais pelo Conselho Nacional de Política Criminal e Penitenciária (Resolução № 3 de 11/03/2009 do CNPCP) e das Diretrizes Nacionais para a oferta de educação para jovens e adultos privados de liberdade nos estabelecimentos penais pelo Conselho Nacional de Educação (Parecer CNE/CEB oㅡ 4/2010 e Resolução CNE/CEB no 2 de 19/05/2010) e, consequentemente, a alteração na Lei de Execução Penal que tem como prerrogativa ao reeducando a remissão de pena por estudo.

Todavia, embora existam normativas e avanços concretos no que tange à educação como proposta de emancipação e humanização do indivíduo no contexto do cárcere, ainda há muito que evoluir. Devemos promover discussões e ações que visem não apenas às políticas educacionais aos apenados, mas também viabilizar diálogos com a comunidade, a fim de sensibilizar a sociedade quanto ao seu papel de acolher o egresso após seu cumprimento de pena, dando a ele oportunidade de ser reinserido na sociedade e no mundo do trabalho, podendo ser um cidadão crítico e atuante, contribuindo para a melhoria de sua vida e do espaço em que está inserido.

Atualmente, a sociedade tem uma opinião paradoxal diante da situação do recluso e sua reinserção. Se, por um lado, ela é contrária a investimentos oriundos de verba pública na educação dos reclusos, por outro lado, reafirma o discurso de que o preso precisa "mudar de vida" para ser reinserido na sociedade. Segundo Rizzi (2013), esta é

[...] uma visão forte entre gestores e sociedade de que o ensino para presos é "privilégio". A violação do direito à educação é mais uma das violações que ocorrem no nosso sistema prisional. A pena no Brasil diz respeito à privação de liberdade. Os outros direitos - à educação, à saúde, à dignidade humana - têm de ser respeitados (p. 03).

Estudos apontam que a população carcerária tem crescido quase que exponencialmente. Este é um problema social, pois os presídios já não estão mais comportando a demanda de pessoas. De acordo com os dados do Levantamento Nacional de Informações Penitenciárias (Infopen) divulgados em 2017, referentes a junho de 2016, a população carcerária brasileira compreendia 726.712 pessoas, das quais 16.917 pertencem ao Estado de Goiás.

O Departamento Penitenciário Nacional (Depen) destaca, em 2017, por meio do Infopen, que a população carcerária aumentou $707 \%$, tendo em vista os 
registros do início da década de 90 . Sendo assim, é mais que urgente refletirmos acerca da educação no sistema prisional, pois ao final do cumprimento de suas penas, essas pessoas voltarão a conviver em sociedade. Se, ao longo de seus encarceramentos, esses apenados não tiverem desenvolvido pensamento crítico propiciado por uma educação emancipadora que visa à formação integral e, para além, não estiverem preparados para serem reinseridas no mundo do trabalho, certamente voltarão a delinquir.

Dados do Depen (2017) revelam o perfil da população carcerária do Estado de Goiás e sugerem que fatores como baixa escolaridade, raça, faixa etária e outros estão diretamente relacionados com o sujeito que cumpre pena restritiva de liberdade.

Segundo essa pesquisa, $60 \%$ dos reclusos que cumprem pena no sistema prisional de Goiás possuem a faixa etária entre 18 e 29 anos, ou seja, encontram-se em idades economicamente ativas, em idades laborativas. Esses jovens poderiam estar inseridos no mundo do trabalho, desenvolvendo suas habilidades, tendo o trabalho como elemento formativo e a educação como princípio educativo (MARX, 1980).

Em relação à escolaridade desses reeducandos, $35 \%$ possuem o ensino fundamental incompleto, $18 \%$ concluíram o ensino fundamental, $16 \%$ são alfabetizados (sem cursos regulares), $15 \%$ possuem 0 ensino médio incompleto, $8 \%$ possuem o ensino médio completo, $7 \%$ são analfabetos e apenas $1 \%$ possui o ensino superior incompleto (DEPEN, 2017). Essa realidade apresentada pelo sistema prisional brasileiro, mais especificamente no estado de goiano, levanta reflexões sobre o quanto a educação formal está distante da realidade desses presos, pois mais da metade dessa população carcerária ainda não acessou o ensino médio, concluíram, no máximo, o ensino fundamental. Por isso a urgência em investimentos na educação, principalmente no cerne do sistema penitenciário.

Com o advento da Lei 12.433/11 que altera a Lei de Execução Penal (LEP), a fim de dispor acerca da remição de parte do tempo de execução da pena por estudo ou por trabalho, é possível facilitar o acesso do reeducando à educação formal, porém veremos que ainda é uma realidade distante de ser alcançada. Nesse sentido, a legislação, em seu artigo 126, parágrafo 1ํㅡ, preconiza que a contagem de tempo será realizada da seguinte forma:

I - 1 (um) dia de pena a cada 12 (doze) horas de frequência escolar - atividade de ensino fundamental, médio, inclusive profissionalizante, ou superior, ou ainda de requalificação profissional - divididas, no mínimo, em 3 (três) dias;

II - 1 (um) dia de pena a cada 3 (três) dias de trabalho (BRASIL, 2011, n.p.).

A problemática encontrada está no fato de que, embora haja a remissão de pena tanto para o estudo quanto para o trabalho, o diferencial está na remuneração atrelada à atividade laboral, fazendo com que a ascensão 
econômica do encarcerado seja imediata, enquanto que por meio dos estudos é em longo prazo.

No contexto do sistema prisional da cidade de Aparecida de Goiânia, maior penitenciária do estado de Goiás, sendo a única que possui uma escola dentro de sua estrutura, os horários resguardados ao estudo e ao trabalho acontecem paralelamente e cabe ao preso escolher entre trabalhar e estudar, considerando a quantidade de vagas disponíveis, as quais não atendem a grande demanda da população carcerária. Por isso é fundamental refletir sobre a oferta, no sistema prisional, de uma educação integral balizada por seus princípios formativos e emancipadores, capaz de possibilitar ao reeducando uma formação crítica, autônoma e omnilateral.

[T]al educação requer não apenas formação que articule a competência científica e técnica com a inserção política e a postura ética, mas também a capacidade de produzir e aplicar os conhecimentos técnicos e científicos, através de critérios de relevância social e ética (VIEIRA, 2014, p. 08).

A referência a esse tipo de educação é devida à possibilidade da formação plena do indivíduo, tanto para a vida quanto para o mundo do trabalho, contemplando ainda a concessão de auxílio financeiro ao estudante, como amparo às necessidades sociais básicas em decorrência da vulnerabilidade social.

Neste sentido, Gramsci legitima a ideia de que a educação seja unitária, capaz de formar o jovem até a fase de sua escolha profissional "[...] formandoo, nesse meio tempo, como pessoa capaz de pensar, de estudar, de dirigir ou de controlar quem dirige" (GRAMSCI, 1977, p. 1547).

Os dados revelam que, apenas 506 reclusos (3\%) estão envolvidos em atividades de ensino escolar e somente 23 envolvidos em atividades educacionais complementares, como a remissão de pena pela leitura ou pelo esporte, enquanto 1.821 presos (11\%) estão em atividade laboral (DEPEN, 2017). Diante desse cenário, é inevitável refletir e indagar: a quem serve esse sistema capitalista e desumano que está posto nos intramuros dos presídios disfarçados de "boas ações"? Esse Sistema serve às grandes empresas que buscam apenas se furtarem do pagamento de direitos trabalhistas concedidos aos trabalhadores apenados, exploração de mão de obra barata e isenção fiscal, possuem infraestrutura física improvisada e precária, além de não terem despesas com o fornecimento de água e energia, já que estes estão sendo custeados pelo Estado. Nesses locais, grande parte dos presos trabalham oito horas por dia em pé, sem poder sentar-se, e o salário pago a eles é inferior a um salário mínimo. Não se trata de defender a ociosidade e a improdutividade humana, mas de defender a dignidade do sujeito, resguardada pela Constituição Federal, em seu artigo 1, inciso III, no qual é garantido o respeito aos direitos da pessoa, tanto pela sociedade quanto pelo poder público, assegurando a valorização do ser humano (BRASIL, 1988). Nesse contexto, Julião (2011) afirma: 
[p]ara a criminologia crítica qualquer reforma que se possa fazer no campo penitenciário não terá maiores vantagens, visto que, mantendo-se a mesma estrutura do sistema capitalista, a prisão manterá a sua função repressiva e estigmatizadora (p. 144).

Para que o encarceramento tenha sua finalidade ressocializadora, fazemse necessárias mudanças estruturais no sistema prisional, quebra de paradigmas e de concepções que tenham apenas como resultado a punibilidade, mas, para além do ato de punir, é profícuo educar, reeducar, emancipar, reintegrar e humanizar o indivíduo que cumpre pena restritiva de liberdade. A mera punição, ou seja, apenas o confinamento não evitará que o reeducando volte a delinquir após cumprir sua pena e retornar para a sociedade, e novamente a comunidade será prejudicada, pois não possui meios para enfrentar essa realidade e, então, outra vez se tornará vítima da violência cometida por infratores que não se ressocializaram dentro do sistema prisional.

É possível implementar ações viáveis que promovam transformações no sistema penitenciário, apesar de sabermos que todos os problemas inerentes a ele não se resolverão de forma tão rápida, haja vista as limitações que o permeiam. No entanto, são exequíveis alternativas capazes de amenizar a problemática do sistema carcerário priorizando a humanização, emancipação e ressocialização do apenado, como função precípua na redução do índice de reincidência na criminalização. Nesse sentido, Brandão e Farias (2013) apontam que é dever do Estado elaborar políticas que visem à inclusão social de reclusos e egressos, a fim de desenvolverem seus potenciais enquanto indivíduos, cidadãos e profissionais. Essas mudanças nas instituições carcerárias são possíveis por meio da educação e do trabalho, contudo é imprescindível realizar investimentos, seja financeiro, seja de profissionais capacitados e preparados para atuarem nesse ambiente repleto de especificidades, ou seja, de tempo para estudar o contexto em que os reclusos estão inseridos para propor melhorias (SOUZA; SILVEIRA, 2017). Existem vários caminhos a serem percorridos, porém pergunta-se: quem está disposto a percorrê-los?

A reflexão acerca da proposta de humanização e emancipação dos reeducandos do sistema prisional leva a refletir sobre a concepção de Manacorda (1996) em relação ao trabalho e à educação, no sentido dessa formação no contexto do cárcere ser, para além do mercado de trabalho, uma formação integral do indivíduo, omnilateral. Nesse sentido, Julião (2009) aponta que

[é] preciso valorizar uma concepção educacional que privilegie e ajude a desenvolver potencialidades e competências que favoreçam a mobilidade social dos internos e não os deixem se sentir paralisados diante dos obstáculos que serão encontrados (p. 05). 
Mesmo diante do ineficiente quantitativo de vagas para atender a demanda da população carcerária da Penitenciária Coronel Odenir Guimarães, os reeducandos que cumprem pena nesse presídio buscam, por iniciativa própria, meios de desenvolverem atividade laboral como possibilidade de preencherem 0 tempo ocioso e de obterem recursos financeiros para se manterem, já que o Estado oferece apenas três refeições diárias e não arca com nenhum outro tipo de insumo necessário à manutenção da vida do encarcerado, como materiais de higiene, limpeza e vestuário (uniforme). As atividades de trabalho desenvolvidas pelos reclusos compreendem a confecção de artesanatos e alimentos, como mostram as Figuras 1 e 2.

Figura 1 - Trabalhos manuais desenvolvidos pelos reeducandos da Penitenciária Coronel Odenir Guimarães

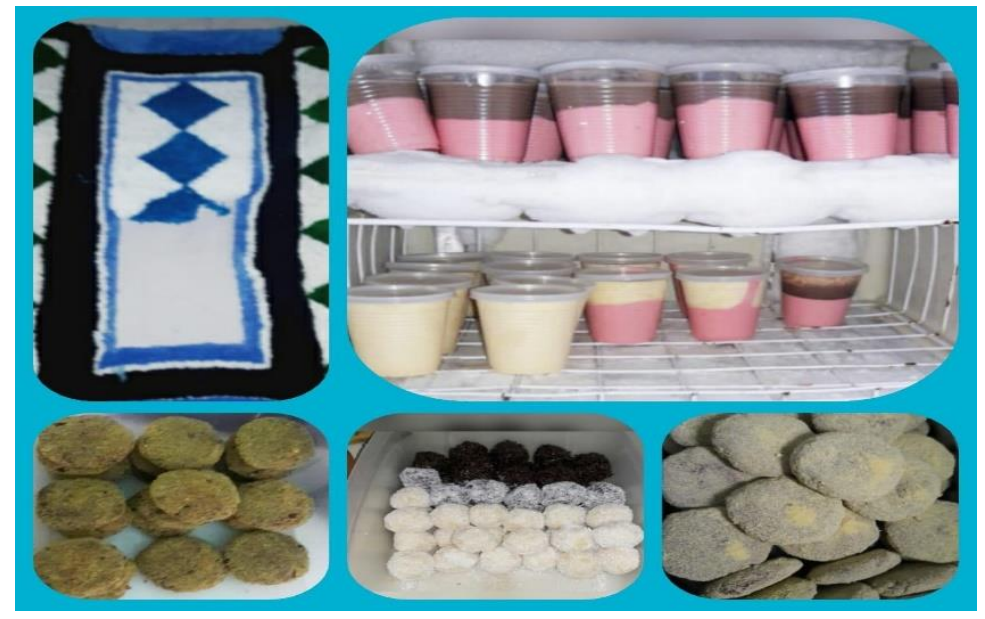

Fonte: Arquivo da autora.

Figura 2 - Tapetes artesanais confeccionados por reeducandos da Penitenciária Coronel Odenir Guimarães

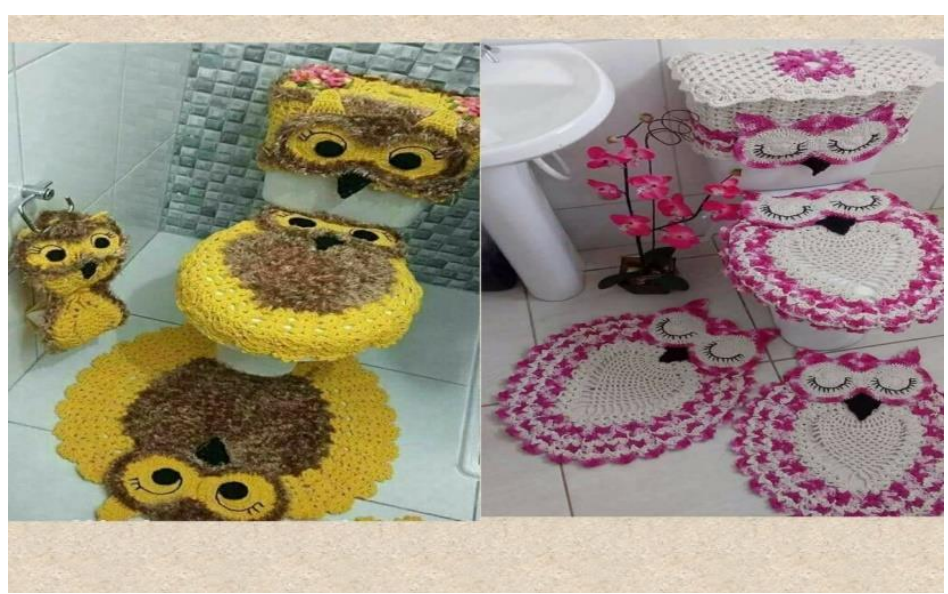

Fonte: Arquivo da autora. 
Uma das mazelas enfrentadas pelos reclusos é em relação ao tempo ocioso. São muitos anos cumprindo penas restritivas de liberdade, o que faz com que busquem alternativas para dirimirem a ociosidade. Dessa forma, além do caráter econômico atribuído pelo capitalismo, o trabalho manual traz também a possibilidade de externarem seus conhecimentos e potencialidades, mesmo que de forma simples como na produção de tapetes e comidas. Desse modo, eles se reconhecem na produção desses materiais como algo intrínseco a eles, proporcionando a ocupação não apenas do tempo, mas também da mente. Essas iniciativas dos reeducandos em produzirem seus próprios meios de sobrevivência, corroboram os ideais de que o trabalho constitui parte da essência humana, para produzir a sua existência o homem transforma a natureza, modifica o meio em que vive com a finalidade de garantir a sua subsistência. Saviani (1991) enfatiza que

[d]iferentemente dos outros animais, que se adaptam a realidade natural tendo sua existência garantida naturalmente, o homem necessita produzir continuamente sua própria existência. Para tanto, em lugar de se adaptar à natureza, ele tem que adaptar a natureza a si, isto é, transformá-la. E isto é feito pelo trabalho. Portanto, o que diferencia o homem dos outros animais é o trabalho [...] (p. 01).

A educação e o trabalho se relacionam e se complementam e por meio dessa relação o ser humano é capaz de se reinventar, se transformar modificando tudo que está a sua volta, promovendo uma nova concepção de vida, da existência humana. Shecaira e Corrêa Junior (1995) afirmam que ressocializar é a efetiva reinserção social, a criação de mecanismos e condições a fim de que a pessoa possa retornar ao convívio social sem traumas ou sequelas, podendo, então, viver uma vida normal. Assim, para que ela seja realizada de forma profícua, deverá ser composta por três pilares fundamentais que são: educação, capacitação profissional e trabalho. Nessa perspectiva, elencamos algumas possibilidades para a promoção da emancipação e humanização do apenado, com vistas à ressocialização e integração à sociedade após o cumprimento de pena. São elas:

- palestras educativas e motivacionais;

- oficinas de trabalho;

- implantação da EJA no turno noturno dos presídios, a fim de ampliar o acesso à educação daqueles que trabalham durante o dia;

- cotas em instituições de ensino técnico e superior para egressos do sistema carcerário e par pessoas que cumprem pena restritiva de liberdade no regime semiaberto;

- ofertas de cursos técnicos e profissionalizantes em parceria com o Sistema S e Institutos Federais em consonância com bolsas de estudo.

Esses são alguns caminhos que podem ser percorridos como propostas que vão ao encontro de possibilidades de transformações no que tange à 
reinserção do reeducando ao cerne da sociedade, embora essas não se esgotem aqui. Além dessas, são necessárias muitas outras ações, no entanto discutir essa problemática já é o início de possíveis mudanças no contexto do sistema prisional.

\section{CONSIDERAÇÕES FINAIS}

A população carcerária no país cresceu em proporções jamais vistas em nossa sociedade e isso é alarmante, principalmente considerando o alto índice de reincidência criminal. De acordo com o Depen (2017), a população prisional cresceu cerca de $7,3 \%$ ao ano, passando de 232 mil pessoas no ano de 2000 para 726 mil em 2016. Nesse sentido, a Educação Profissional, Técnica e Tecnológica é uma possibilidade para diminuir a reincidência no mundo do crime, e ampliar a escolarização dessas pessoas que cumprem pena restritiva de liberdade, já que possuem baixa escolaridade e, portanto, não tiveram acesso a uma educação integral, conforme apresentamos nesta pesquisa documental, por meio dos dados do Depen.

A educação para o mundo do trabalho é essencial na formação dos reeducandos, pois possibilitará a reinserção deles na sociedade, permitindo que se reconheçam enquanto cidadãos críticos, atuantes e responsáveis por transformar o lugar em que estarão inseridos, de forma positiva.

Para isso, este artigo reflete acerca da proposta de uma formação emancipadora, omnilateral, integradora e libertadora que humanize, com vistas a atribuir sentido e significado a existência dos apenados, a fim de possibilitar que se tornem profissionais autônomos e participativos. Essa formação é possível por meio da implementação das propostas de currículo integrado que visem à escolarização do indivíduo em consonância com a educação profissional, tendo como eixo norteador a concepção de formação humana integral e o trabalho como princípio educativo.

\section{REFERÊNCIAS}

BRANDÃO, Jammilly Fagundes; FARIAS, Angélica. Inclusão Social de ExDetentos no Mercado de Trabalho: Reflexões acerca do Projeto Esperança Viva. In: ENCONTRO DE GESTÃO DE PESSOAS E RELAÇÕES DE TRABALHO, 2013, Brasília. Anais [...] Brasília: Associação Nacional de PósGraduação pesquisa em Administração - ANPAD, 2013.

BRASIL. [Constituição (1988)]. Constituição da República Federativa do Brasil de 1988. Brasília, DF: Senado Federal, Centro Gráfico, 1988.

BRASIL. Lei de Execução Penal no 7.210, de 11 de julho de 1984. Institui a Lei de Execução Penal. Brasília, Senado Federal, 2018. Disponível em: http://www.planalto.gov.br/ccivil_03/LEIS/L7210.htm. Acesso em: 12 out. 2018. 
BRASIL. Lei o 13.005 de 25 de junho de 2014. Aprova o Plano Nacional de Educação. Diário Oficial da União, Brasília, DF, p. 1, 26 jun. 2014b. Seção 1, Edição Extra.

BRASIL. Lei no 12.433, de 29 de junho de 2011. Altera a Lei o 7.210, de 11 de julho de 1984 (Lei de Execução Penal), para dispor sobre a remição de parte do tempo de execução da pena por estudo ou por trabalho. Diário Oficial da União, Brasília, DF, 29 jun. 2011. Disponível em: http://www.planalto.gov.br/CCiVil_03/_Ato2011-2014/2011/Lei/L12433.htm. Acesso em: 24 nov. 2020.

BRASIL. Ministério da Justiça e Segurança Pública. Departamento Penitenciário Nacional. Levantamento nacional de informações penitenciárias.

Atualização - junho de 2017. Brasília: Departamento Penitenciário Nacional, 2017. Disponível em: \&amp;lt;http://depen.gov.br/DEPEN/noticias1/noticias/infopen-levantamento-nacional-de- informacoes-penitenciarias2016/relatorio_2016_22111.pdf\&amp;gt;. Acesso em: 10 maio 2019.

CIAVATTA, Maria. A formação integrada: a escola e o trabalho como lugares de memória e de identidade. Trabalho Necessário, Niterói, v. 3, n. 3, 2005.

FREIRE, Paulo. Educação como prática da liberdade. Rio de Janeiro: Paz e Terra, 2015.

GIL, Antonio Carlos. Métodos e técnicas de pesquisa social. 5.ed. São Paulo: Atlas, 1999.

GRAMSCI, Antonio. Cadernos do cárcere. Os intelectuais. O princípio educativo. Jornalismo. 2. ed. Rio de Janeiro: Civilização Brasileira, 2001. v. 2. JULIÃO, Elionaldo Fernandes. A ressocialização através do estudo e do trabalho no sistema penitenciário brasileiro. 2009. Tese (Doutorado) Programa de Pós-Graduação em Ciências Sociais do Instituto de Filosofia e Ciências Humanas da Universidade do Estado do Rio de Janeiro, Rio de Janeiro, 2009.

JULIÃO, Elionaldo Frnandes. A ressocialização por meio do estudo e do trabalho no sistema penitenciário brasileiro. Em Aberto, Brasília, v. 24, n. 86, p. 141-155, nov. 2011. Disponível em:

http://emaberto.inep.gov.br/index.php/emaberto/article/viewFile/2576/1765. Acesso em: 16 set. 2019.

MANACORDA, Mario Alighiero. Marx e a pedagogia moderna. São Paulo: Cortez, 1996.

MARX, Karl. Teorias da mais-valia, história crítica do pensamento econômico. v. 1. Rio de Janeiro: Civilização Brasileira, 1980.

RIZZI, Ester. A luta pelo Direito à educação de pessoas jovens e adultas nas penitenciárias. Educativa, 2013. Disponível em: http://ponte.org/a-lutapelo-direito-a-educacao-de-pessoas-jovens-e-adultas-nas-penitenciarias/. Acesso em: 12 out. 2018.

SAUER, Adeum Hilario; JULIÃO, Elionaldo Fernandes. A educação para jovens e adultos em situação de restrição e privação de liberdade no Brasil: questões, avanços e perspectivas. Ministério da Educação Conselho 
Nacional de Educação. Seminário Educação nas Prisões. Brasília/DF - CNE 23 de abril de 2012 (Documento-Referência).

SAVIANI, Dermeval. Escola e Democracia. 25. ed. São Paulo: Cortez:

Autores Associados, 1991.

SHECAIRA, Sérgio Salomão; CORRÊA JUNIOR, Alceu. Pena e Constituição. São Paulo: RT, 1995.

SOUZA, Rafaelle Lopes; SILVEIRA, Andrea Maria. Egressos do sistema prisional no mercado formal de trabalho: oportunidade real de inclusão social?. Revista de Políticas Públicas, v. 21, n. 2, p. 761-780, 2017. VIEIRA, Elizabeth de Lima. A construção da memória da cultura escolar prisional do Colégio Estadual Mário Quintana: entre o instituído e o instituinte. 2014. Tese (Doutorado) - Programa de Pós Graduação em Memória Social, Universidade Federal do Estado do Rio de Janeiro, Rio de Janeiro, 2014.

VYGOTSKY, Lev Semionovitch. A Formação Social da Mente. São Paulo: Martins Fontes, 1984. 